Corrigendum

\title{
Corrigendum to "Model to Estimate Monthly Time Horizons for Application of DEA in Selection of Stock Portfolio and for Maintenance of the Selected Portfolio"
}

\author{
José Claudio Isaias, Edson de Oliveira Pamplona, and José Henrique de Freitas Gomes
}

Institute of Production Engineering and Management, Federal University of Itajubá, 37500-903 Itajubá, MG, Brazil

Correspondence should be addressed to José Claudio Isaias; joseclaudio.isaias@yahoo.com.br

Received 24 December 2015; Accepted 12 January 2016

Copyright (C) 2016 José Claudio Isaias et al. This is an open access article distributed under the Creative Commons Attribution License, which permits unrestricted use, distribution, and reproduction in any medium, provided the original work is properly cited.

The paper titled "Model to Estimate Monthly Time Horizons for Application of DEA in Selection of Stock Portfolio and for Maintenance of the Selected Portfolio" [1] contains an error in equations set (17). The correct equations set is as follows:

$$
\operatorname{Min} \sum_{t=1}^{f}\left[\sum_{l=1}^{m} \sum_{e=1}^{w}\left(c_{l} d_{e}\right)\left(a_{l k}-b_{e k}\right)^{2}\right]
$$

s.t. $\quad(13)$

f.c. $\quad(15)$

$(16)$

\section{References}

[1] J. C. Isaias, E. D. O. Pamplona, and J. H. D. F. Gomes, "Model to estimate monthly time horizons for application of DEA in selection of stock portfolio and for maintenance of the selected portfolio," Mathematical Problems in Engineering, vol. 2015, Article ID 957893, 14 pages, 2015. 


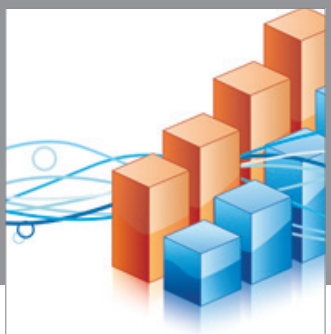

Advances in

Operations Research

vatem alat4

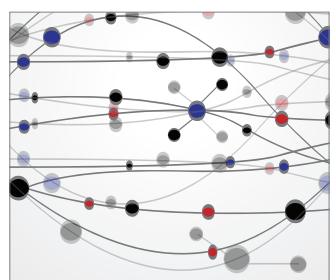

\section{The Scientific} World Journal
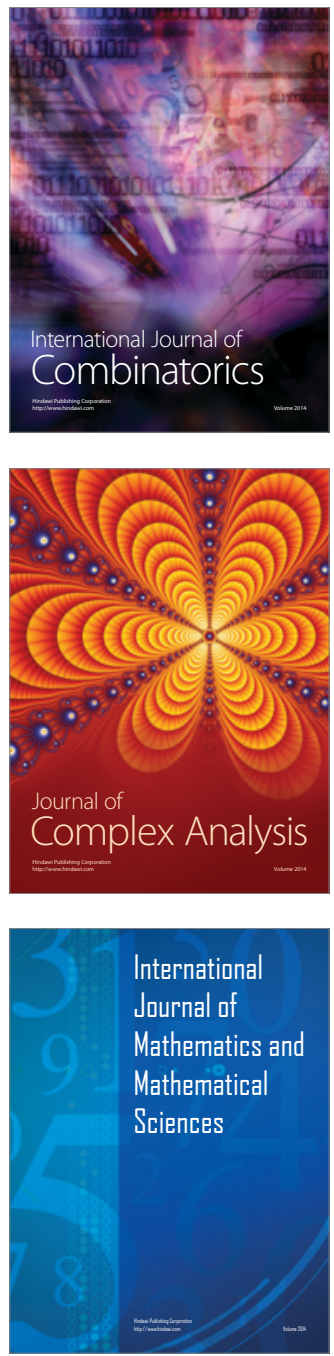
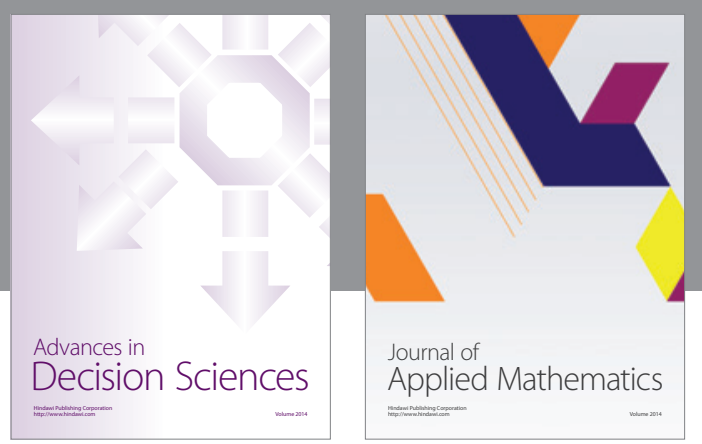

Algebra

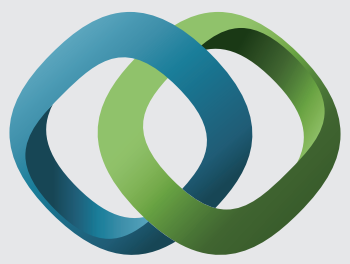

\section{Hindawi}

Submit your manuscripts at

http://www.hindawi.com
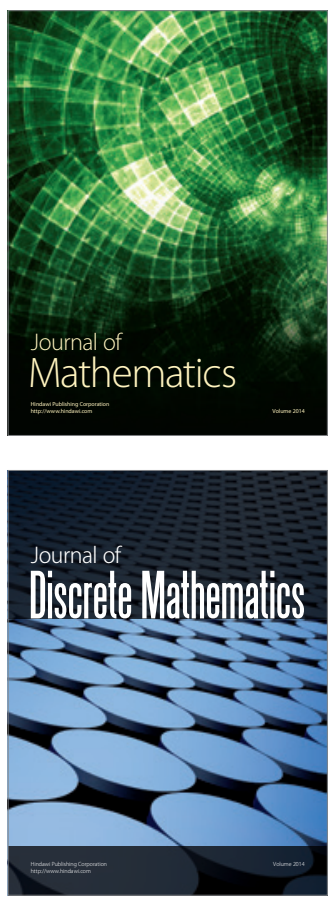

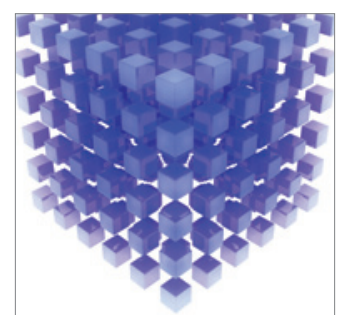

Mathematical Problems in Engineering
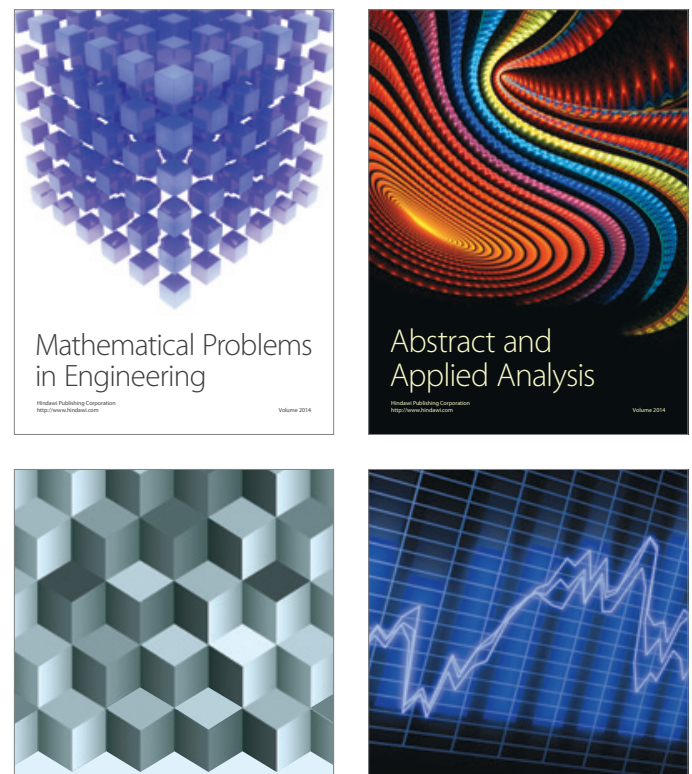

Journal of

Function Spaces

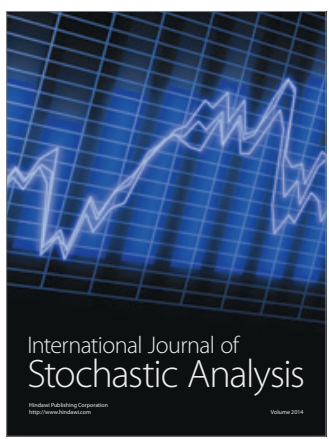

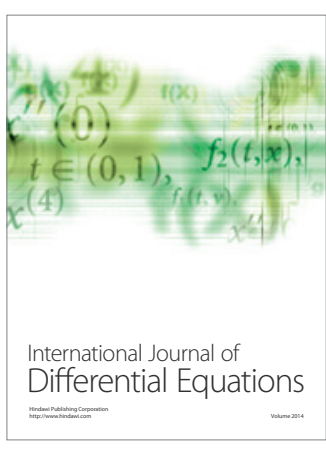
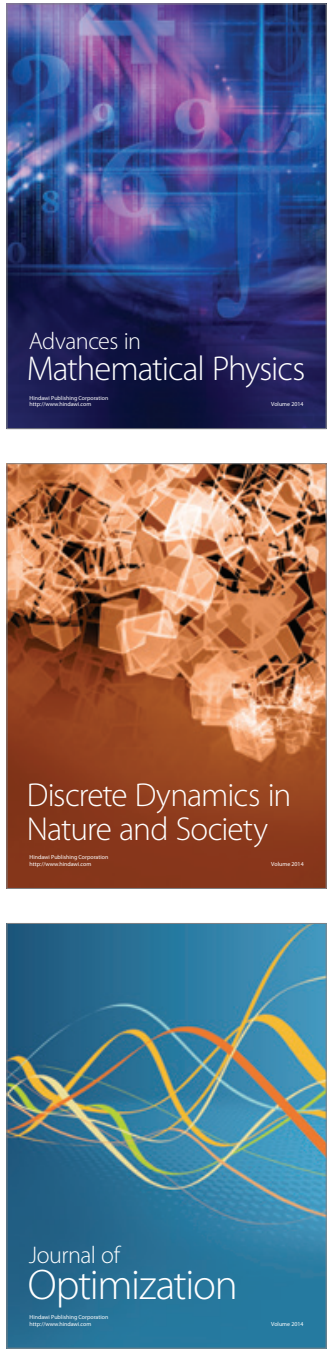